\title{
Analyzing the Heat Transfer Property of Heat Pipe Influenced by Integrated Cooling Apparatus
}

\author{
Chen-Ching Ting ${ }^{1}$ and Chien-Chih Chen ${ }^{2}$ \\ ${ }^{1}$ Department of Mechanical Engineering, National Taipei University of Technology, Taipei 10608, Taiwan \\ ${ }^{2}$ Institute of Mechanical and Electrical Engineering, National Taipei University of Technology, Taipei 10608, Taiwan \\ Correspondence should be addressed to Chien-Chih Chen; t8669030@ntut.edu.tw
}

Received 12 November 2013; Accepted 10 February 2014; Published 11 March 2014

Academic Editors: B. Sun and J. Yuan

Copyright (c) 2014 C.-C. Ting and C.-C. Chen. This is an open access article distributed under the Creative Commons Attribution License, which permits unrestricted use, distribution, and reproduction in any medium, provided the original work is properly cited.

\begin{abstract}
Heat pipe with discrete heat transfer property is often called thermal superconductor because it has extremely large thermal conductivity. This special heat transfer property is destroyed by integrating cooling apparatus and further reducing the cooling power of a heat pipe cooler. This paper experimentally studied the heat transfer property of heat pipe influenced by integrated cooling apparatus. To simplify the investigating process, a home-made square heat pipe with the dimensions of $L \times W \times H=$ $10 \times 10 \times 100 \mathrm{~mm}^{3}$ was built with two pieces of copper plates and two pieces of glass plates face to face, respectively. The two pieces of copper plates were constructed with inside walls of capillary structure and the two pieces of glasses were with antifog inside walls for observing the inner phenomenon. Moreover, isothermal circulating cooling water was applied outside the heat pipe instead of cooling fin. The results show that heat vapor in the heat pipe is condensed earlier and cannot reach the remote section of condenser. In other words, the heat transfer property of heat pipe is destroyed by integrating cooling water. This phenomenon causes the unfavorable cooling power of the heat pipe cooler.
\end{abstract}

\section{Introduction}

Nowadays, advanced fabricating technique in production of semiconductor components provides feasibility to fabricate electronic devices with more precision and high working frequency. The electronic devices with high working frequency in optoelectronics, communication, electric power, aerospace, biomedicine, and so forth often yield extremely large amounts of heat in a small area. Overheat causes the electronic devices to crash or even break. According to Moore's law issued by Intel, the more transistors in a chip also yield the quicker operating speed, but the generated heat by the transistors is also increased. If the transistors cannot be instantaneously and effectively cooled, the hot spots on the chip will appear and damage the transistors. A current popular application of high power LED is the suitable sample. Figure 1 shows junction temperature versus life time for the high power white light LED and indicates that the junction temperature with ca. $10^{\circ} \mathrm{C}$ increment causes the life time to be halved [1].
Cooling normally aims to take waste heat away from the heat source and keep regular work of the electronic products. In general, cooling methods are divided into active and passive in terms of their different working principles. The active cooling uses refrigerating technique to generate cold and forcedly carries heat off through the heat exchange, whereas the passive cooling uses natural thermal convection and removes relatively less energy. The mediums employed in passive cooling are normally metals with large thermal conductivity, fluid with good fluidity for thermal convection and with large latent heat, and air. A lot of cooling technologies, for example, thermal electric cooler (TE Cooler), heat pipe, spray, and so forth, have been plenteously studied and applied, where the TE Cooler is active and the heat pipe and the spray are passive in principle [2-6].

Cooling efficiency cannot reach predicted value which is the main question of a heat pipe cooler. A standard application of heat pipe is in connection with cooling fin which is generally named as heat pipe cooler, but the integration of heat pipe cooler changes the original heat 


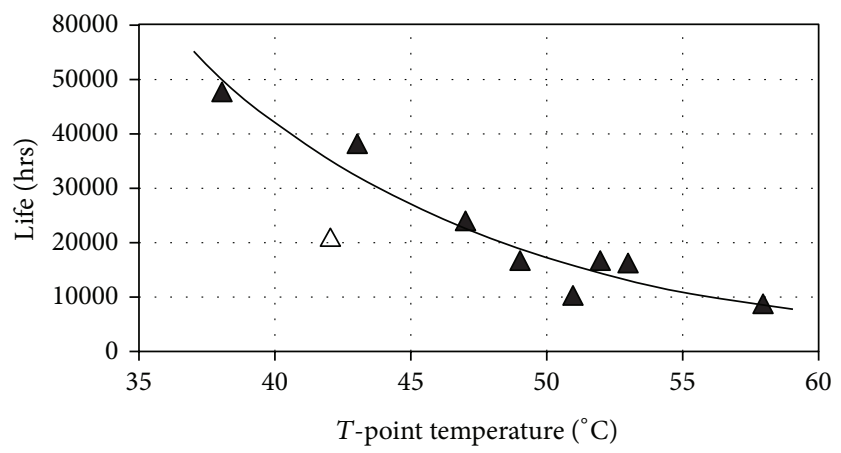

FIGURE 1: Junction temperature versus life time for the high power white light LED [1].

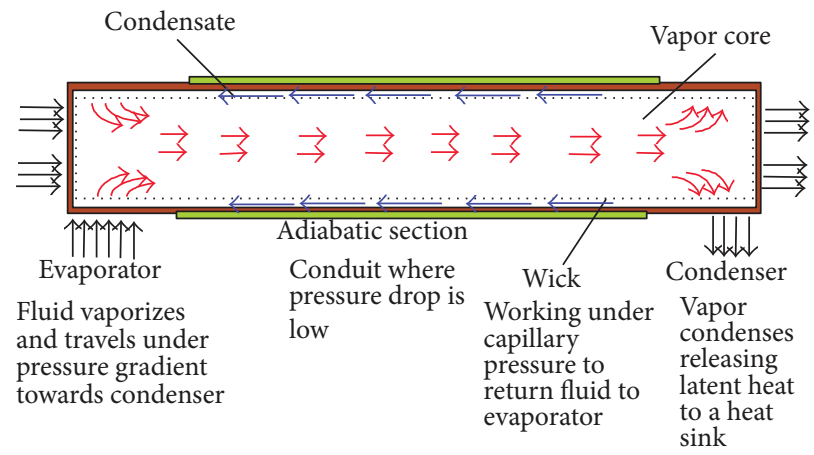

FIGURE 2: Schema description of the working principle for a heat pipe [11].

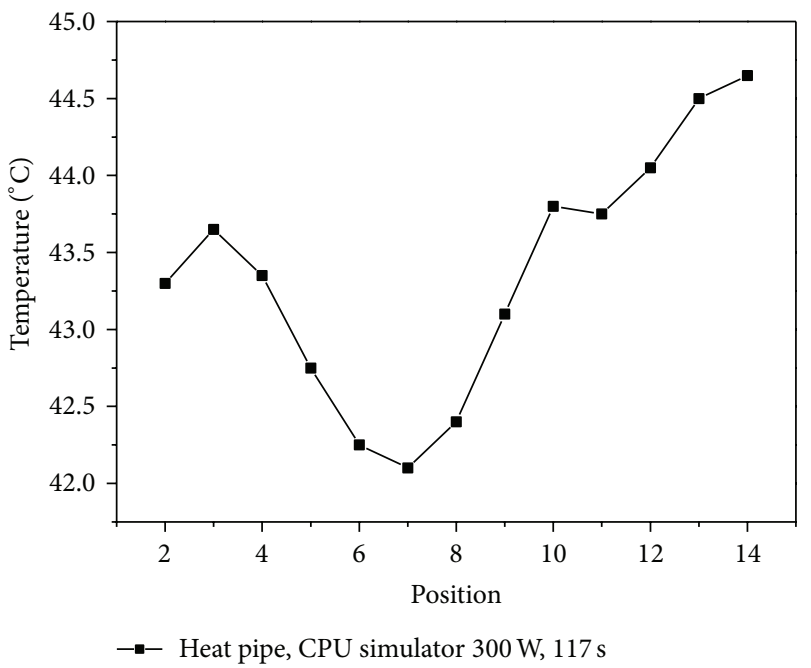

FIGURE 3: Temperature distribution on a bare heat pipe [7].

transfer property of the heat pipe [7]. Most of studies on the heat pipe cooler ignored the considerations of the changed heat transfer behavior for heat pipe and discussed only the integration structure of heat pipe cooler [8-10]. The original heat transfer behavior for heat pipe is discrete and for copper pipe is continuous. This special discrete heat transfer behavior of heat pipe also causes the heat pipe to have the thermal super conduction property.

Experimental studies on the heat transfer behavior inside the heat pipe are relatively few. Ting et al. in 2009 [7] first presented the compared analysis of heat transfer behavior between heat pipe and copper pipe using various experimental methods. Its results show that the heat transfer behavior of heat pipe is destroyed and changed to be similar to copper pipe due to the integration with outside cooling plates in the middle thermal insulating section. Following this research topic, this work further offers more experimental data to study the changed heat transfer behavior inside heat pipe influenced by the added outside cooling apparatus. The changed heat transfer behavior in heat pipe is the main 


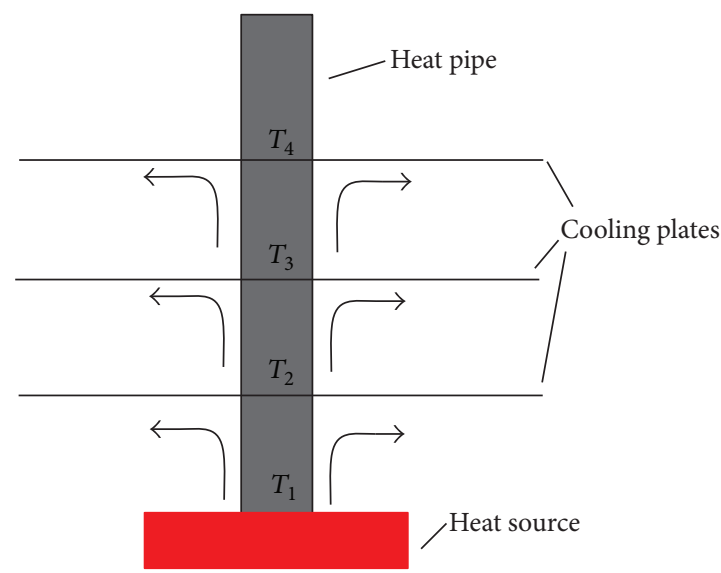

FIGURE 4: Schema of heat pipe integrated with cooling plates.

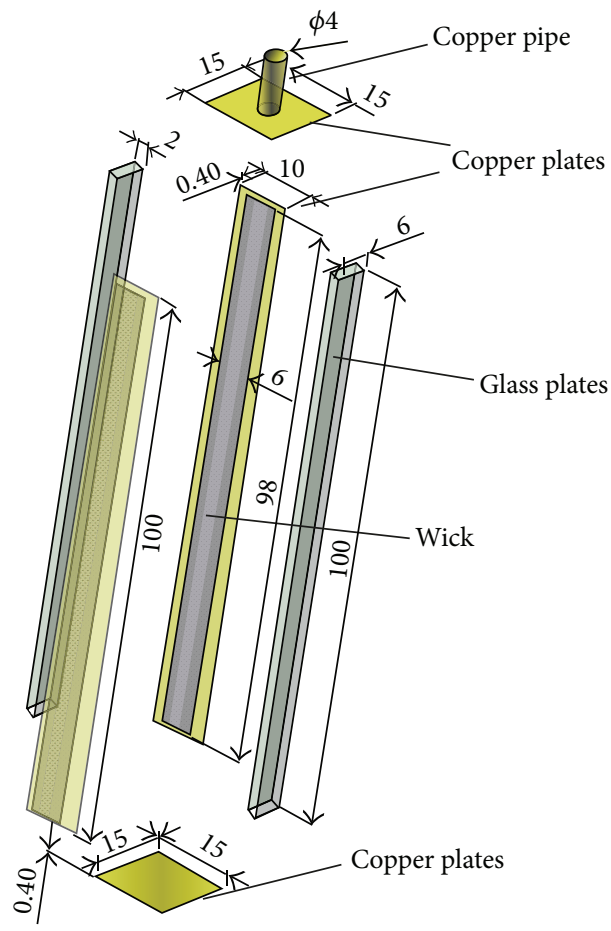

(a) Schema

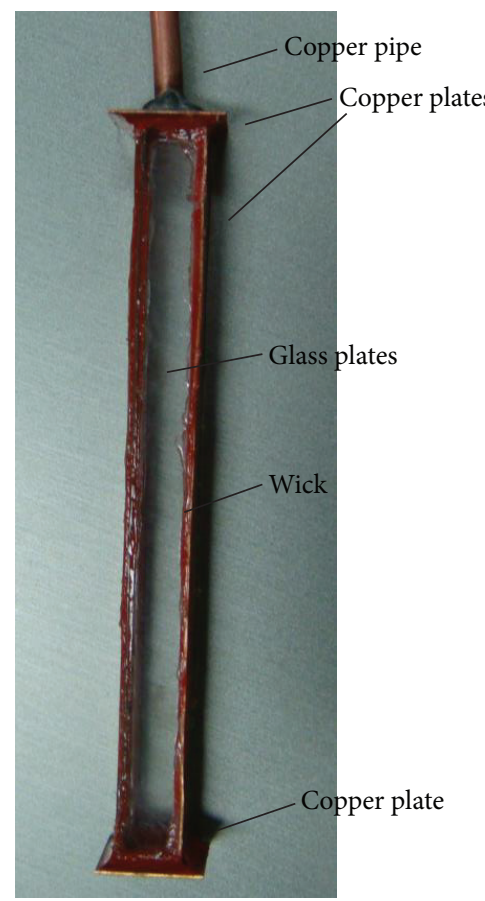

(b) Photo

FIGURE 5: Schema and photo of the home-made square heat pipe.

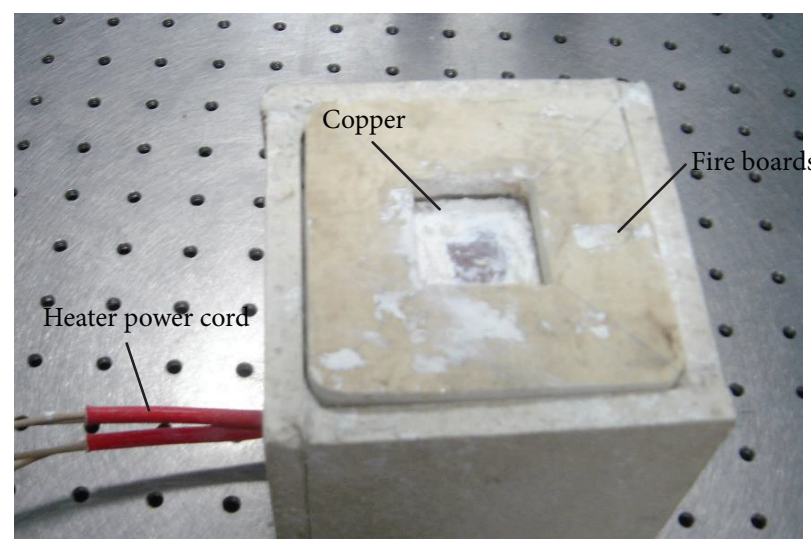

FIGURE 6: Photo of the CPU simulator. 


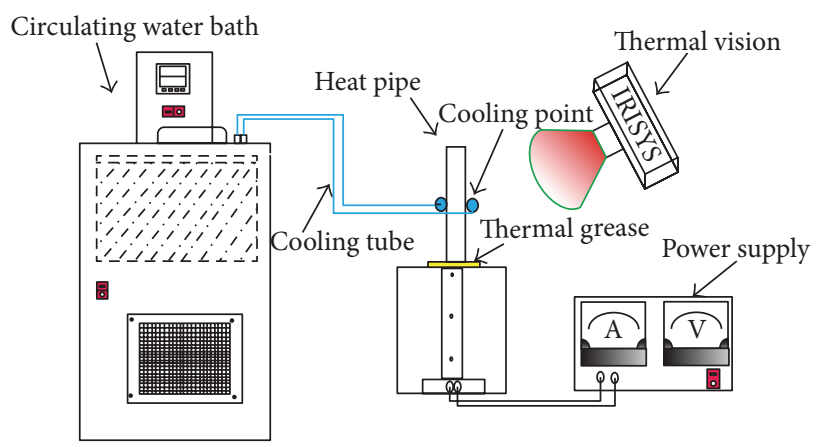

FIGURE 7: Schema of the experimental setup for temperature measurements.

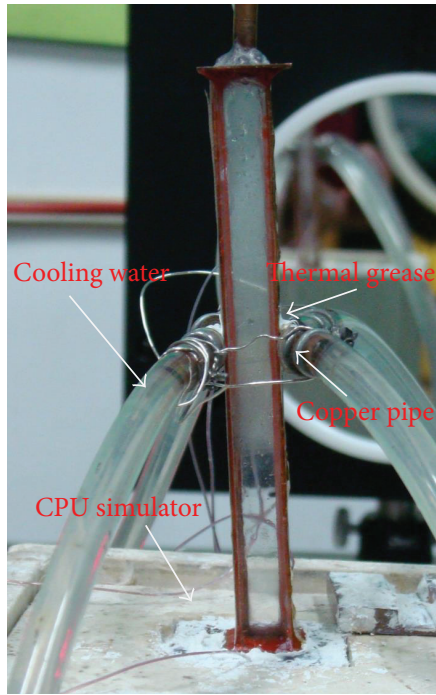

(a)

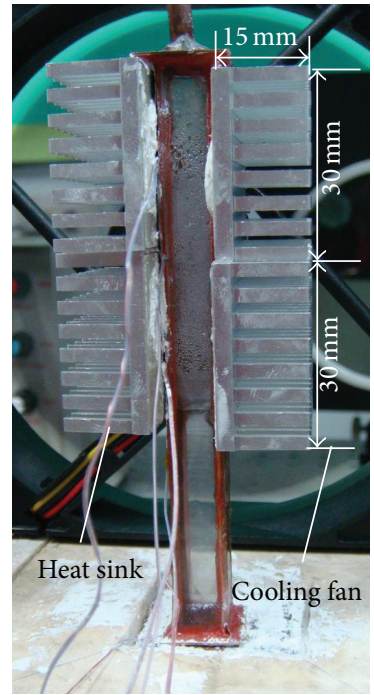

(b)

FIGURE 8: Integration photo of the home-made square heat pipe with outside cooling apparatus.

reason of the lack of cooling efficiency for heat pipe cooler. The heat of vapor inside heat pipe was quickly taken away at the place of the outside cooling apparatus and therefore condensed earlier. This change causes that the cooling plates which are far from the heat source cannot reach sufficient cooling efficiency. To improve the cooling efficiency of heat pipe cooler, a new structure of heat pipe which can keep the original heat transfer behavior of heat pipe after integration with cooling plates should be designed.

\section{Basic Theory}

A heat pipe is a passive cooling device with extremely large thermal conductivity of ca. 5000 30000 [W/mK] which is initiated by a special heat transfer mechanism and can transport relatively large amounts of heat in a tiny temperature difference. A heat pipe uses latent heat of the working fluid through vaporization process to take large amounts of heat away from heat source and the vapor rapidly moves from the heat source to the condensing section for heat transportation.
Figure 2 shows schematic description of its working principle [11-14].

A heat pipe has discrete heat transfer property due to its special heat transfer mechanism. The heating and the condensing sections of a bare heat pipe have higher temperature than the middle thermal insulating section during its working. Figure 3 shows temperature distribution on a bare heat pipe [7], where the position numbers are in correspondence with distances to the heat source.

In general, a heat pipe cooler is a heat pipe integrated with outside cooling fin. The outside cooling fin takes the heat of vapor away and causes the vapor to be condensed earlier. Figure 4 illustrates this phenomenon, where $T$ with subscript numbers are positional temperatures.

\section{Experiment}

Experiments used a home-made square heat pipe with observation window to study the internal heat transfer behavior influenced by external cooling process. The quantitative temperature measurements are performed by using the infrared 


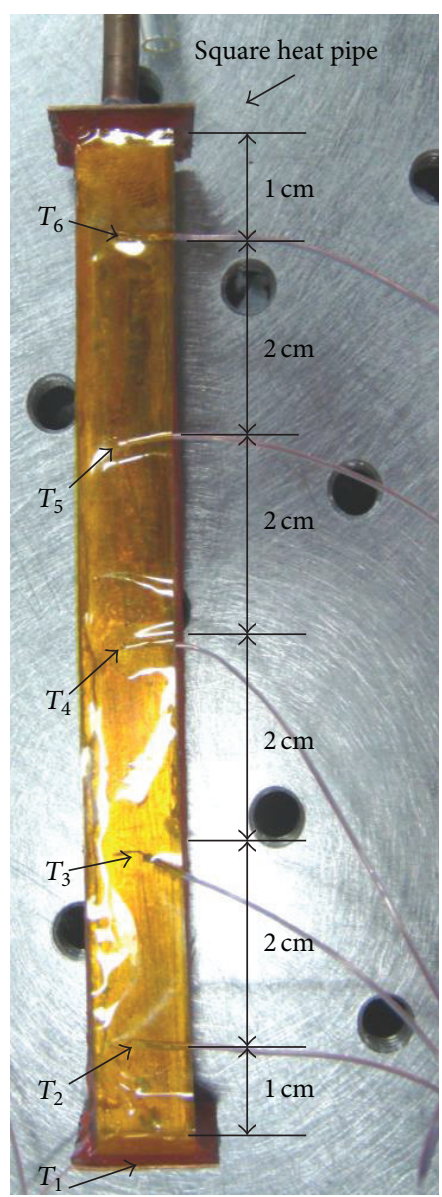

FIGURE 9: Photo of the home-made square heat pipe with temperature measuring points design.

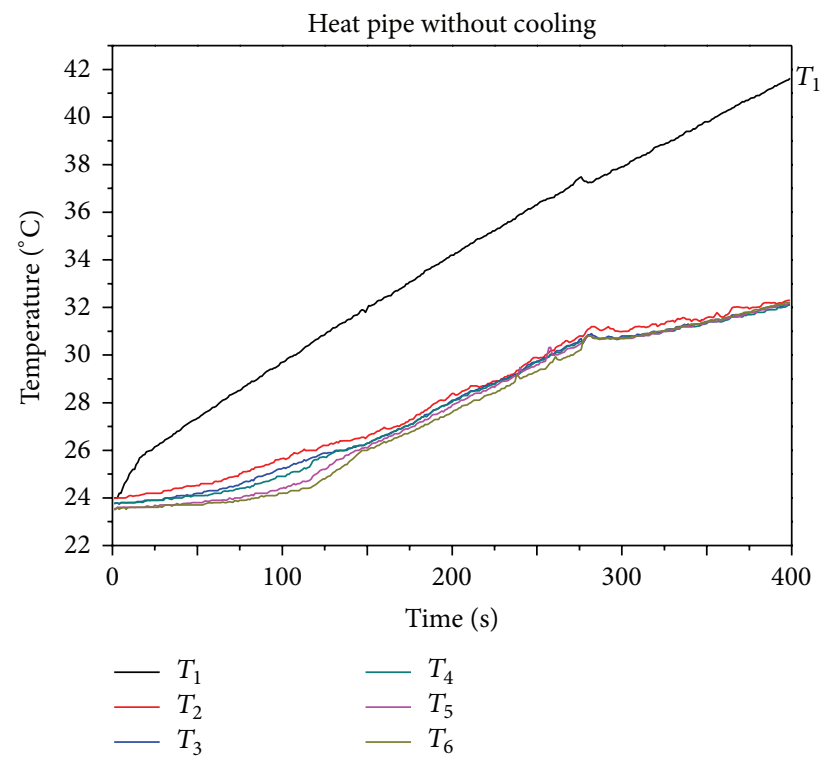

Figure 10: Time dependent surface temperature distribution on the home-made square heat pipe without cooling. 


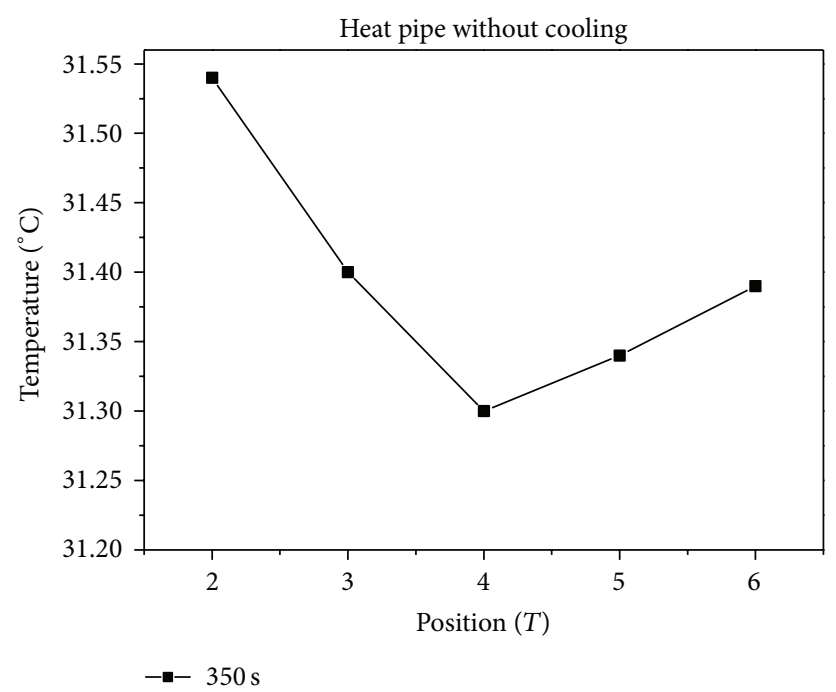

FIGURE 11: Surface temperature distribution on the home-made square heat pipe without cooling, heated in 350 sec.

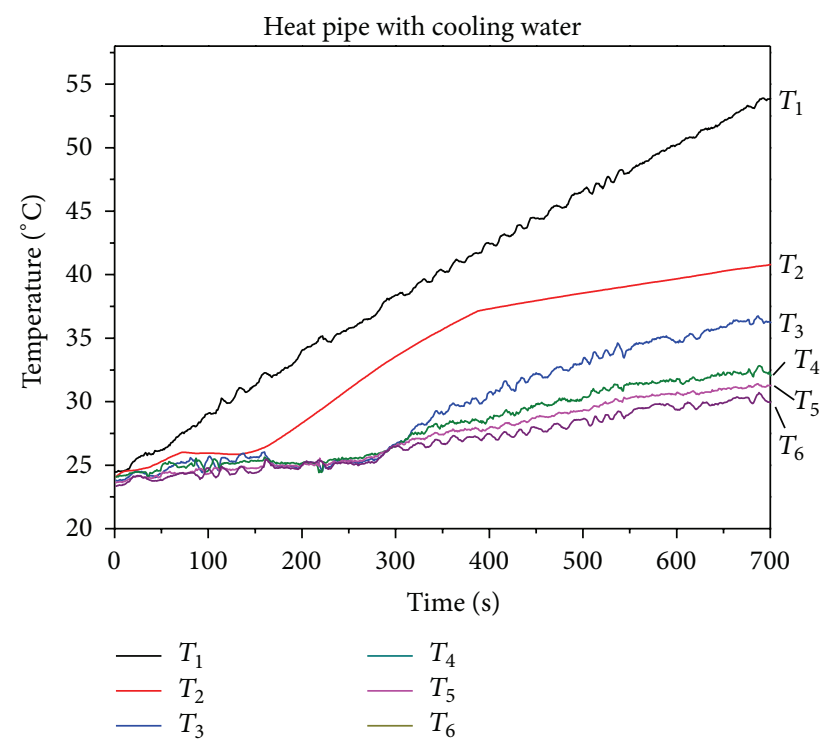

FIGURE 12: Time dependent surface temperature distribution on the home-made square heat pipe integrated with isothermal cooling water.

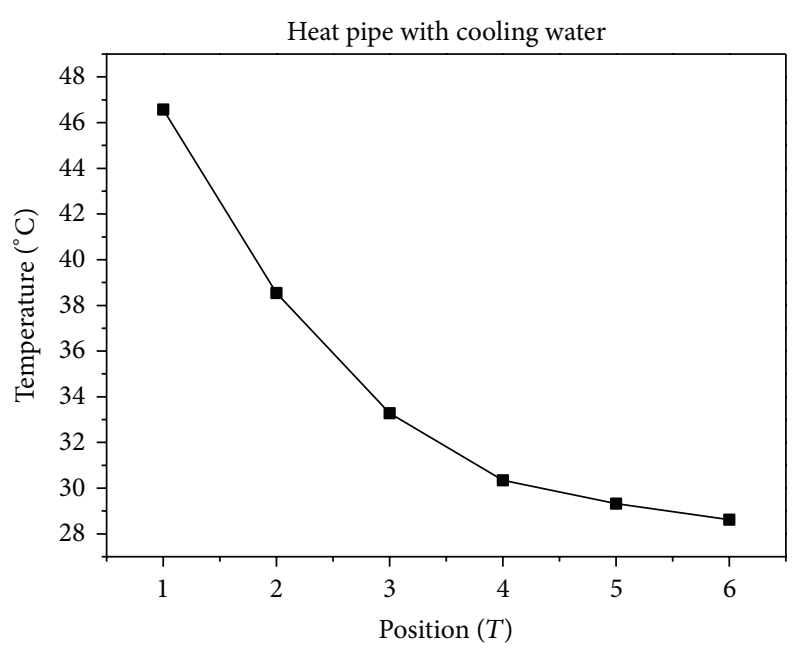

$-500 \mathrm{~s}$

FIGURE 13: Surface temperature distribution on the home-made square heat pipe integrated with isothermal cooling water heated in 500 sec. 


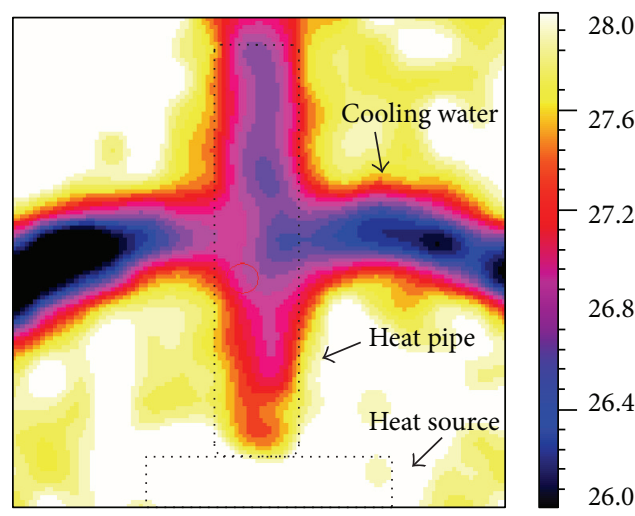

(a) At the beginning

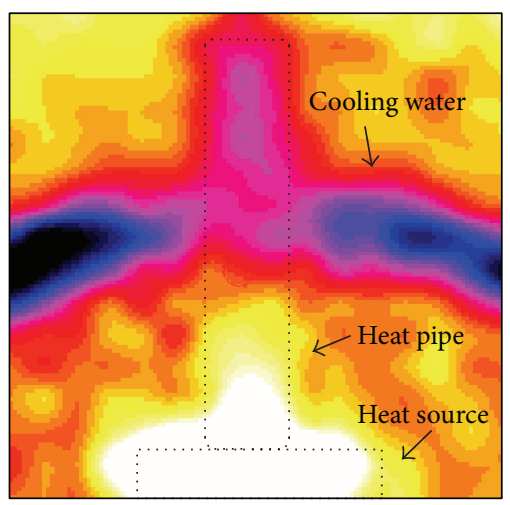

(c) Heated in $200 \mathrm{sec}$

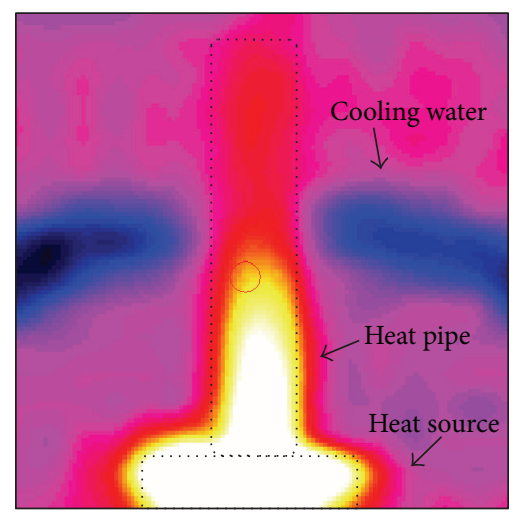

(e) Heated in $400 \mathrm{sec}$

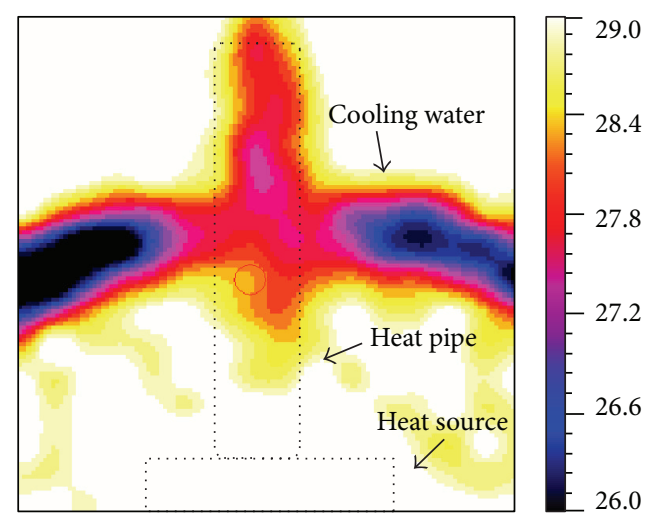

(b) Heated in $100 \mathrm{sec}$
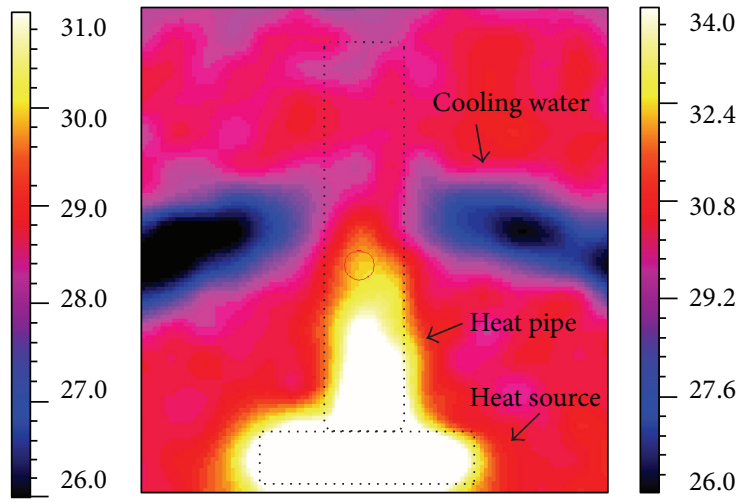

(d) Heated in $300 \mathrm{sec}$
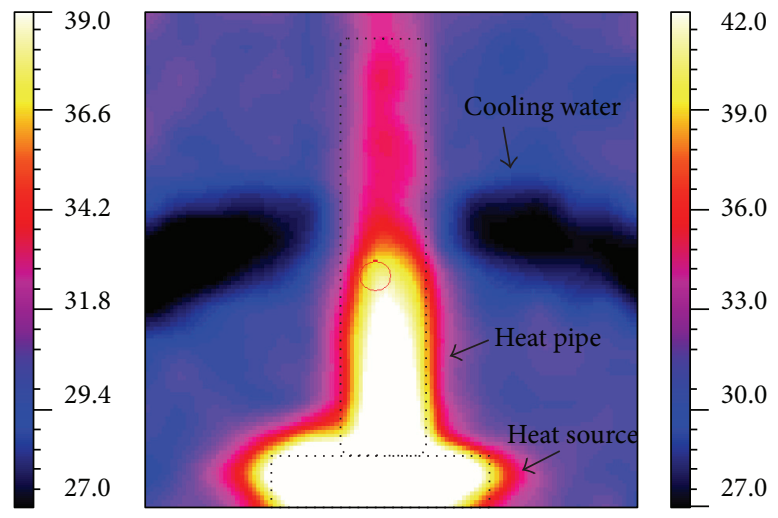

(f) Heated in $500 \mathrm{sec}$

FIGURE 14: Time sequent heat flux visualization of the home-made heat pipe using infrared thermal photography integrated with isothermal cooling water.

thermal photography for two-dimensional data recording in comparison with data measured by the thermocouple thermometer. The experimental setup is detailed in the following subsections.

3.1. The Home-Made Square Heat Pipe. In order to show inner heat transfer property of heat pipe influenced by outer cooling apparatus, this work built a square heat pipe with observation window for synchronous observation inside the heat pipe. The length of the home-made square heat pipe is $100 \mathrm{~mm}$ and its inner width of the square is $6 \mathrm{~mm}$. The four pieces of walls for the home-made square heat pipe are two copper and two glass plates which are built in face to face individually. The inner walls of the home-made square heat pipe on the two copper plates are built in capillary structure with copper mesh and the inner walls of the two glass plates are coated for antifog. Thicknesses of the two copper and glass plates are individually $0.4 \mathrm{~mm}$ and $2 \mathrm{~mm}$. The area of the observation window is $6 \times 100 \mathrm{~mm}^{2}$. One side of the home-made square heat pipe is sealed with a square copper plate for heating and 


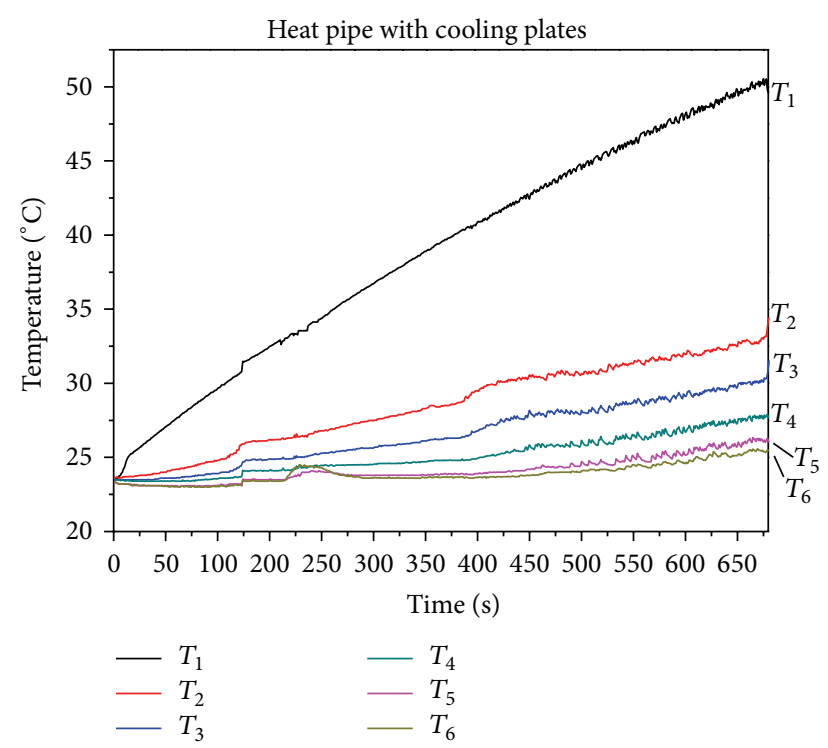

FIGURE 15: Time dependent surface temperature distribution on the home-made square heat pipe integrated with aluminum cooling plates.

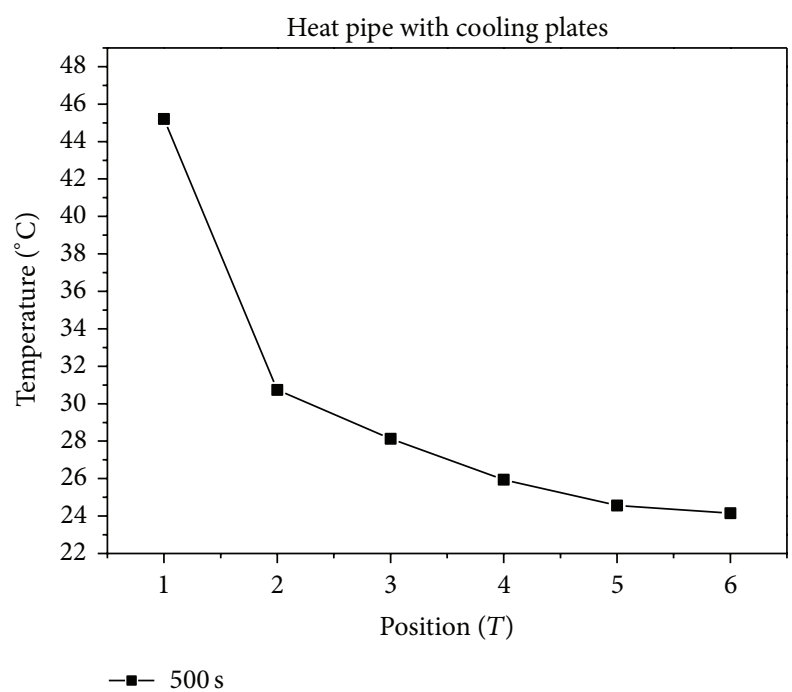

FIGURE 16: Surface temperature distribution on the home-made square heat pipe integrated with aluminum cooling plates heated in 500 sec.

the other side of the square heat pipe is connected with a copper pipe for vacuumization. Figure 5(a) shows schema of the square heat pipe and Figure 5(b) is its photo.

Table 1 shows specifications of the home-made square heat pipe. In the manufacturing process, the two copper plates with copper mesh were sintered by $950^{\circ} \mathrm{C}$ for 60 mins. The filled working fluid in the heat pipe is deionized water of $0.33 \mathrm{~g}$ for $\mathrm{ca} .30$ torr pressure at $24^{\circ} \mathrm{C}$. Its filling process first put deionized water of ca. $0.36 \mathrm{~g}$ into the home-made square heat pipe and then pumped to ca. 30 torr. The working temperature range of the home-made square heat pipe is $20 \sim$ $60^{\circ} \mathrm{C}$.

3.2. The Temperature Measurements. A CPU simulator in accordance with the ASTM D5470 standard was built as the
TABLE 1: Specifications of the home-made square heat pipe.

\begin{tabular}{lccc}
\hline Devices & Scale $(\mathrm{mm})$ & Material & Amount \\
\hline Copper pipe & $\phi=4$ & Copper & 1 \\
Glass plates & $W \times H \times D=6 \times 100 \times 2$ & $\mathrm{SiO}_{2}$ & 2 \\
Copper plates & $W \times H \times D=10 \times 100 \times 0.4$ & Copper & 2 \\
Wick & $W \times H \times D=6 \times 98 \times 0.1$ & Bronze & 6 \\
Copper plates & $W \times H \times D=15 \times 15 \times 0.4$ & Copper & 2 \\
\hline
\end{tabular}

heat source in this work. Its heating area and maximum output power are individually $30 \times 30 \mathrm{~mm}^{2}$ and ca. $300 \mathrm{~W}$. Figure 6 is the photo of the CPU simulator. 


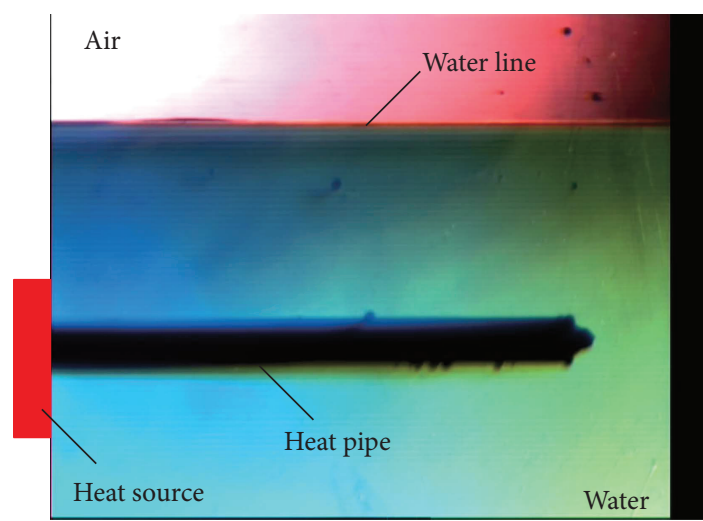

(a) At the beginning

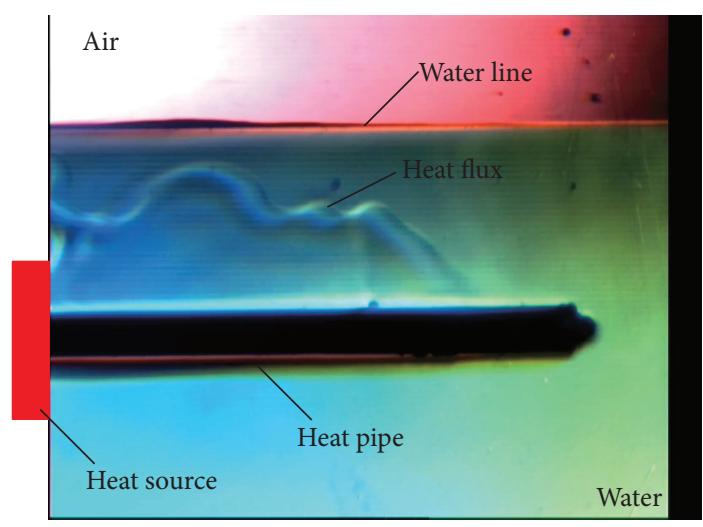

(c) Heated in $18 \mathrm{sec}$

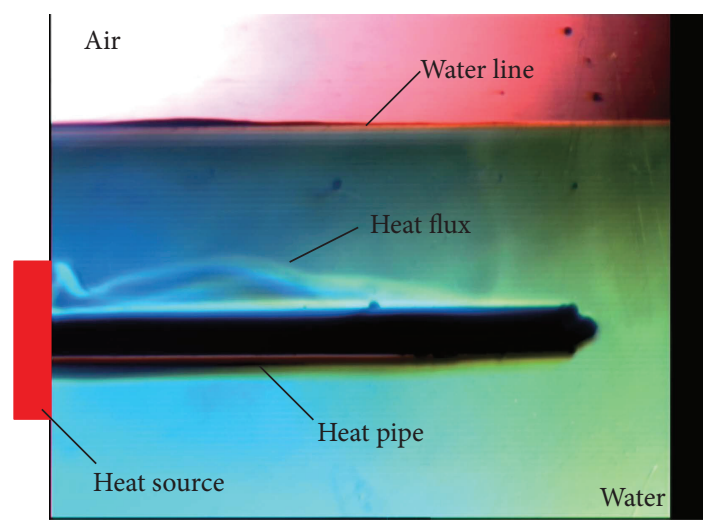

(b) Heated in $15 \mathrm{sec}$

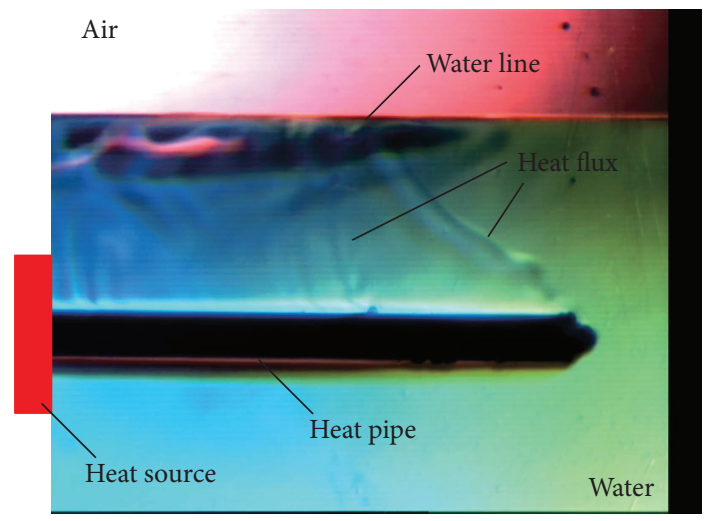

(d) Heated in $22 \mathrm{sec}$

FIGURE 17: Time sequent heat flux visualizations of heat pipe in water using color schlieren technique.

Figure 7 shows schema of the experimental setup for temperature measurements. There are two types of cooling apparatus in this work. One is the isothermal cycling water through a copper pipe in connection with outside copper walls of the home-made square heat pipe in different positions. The other is the aluminum cooling fin which is applied as the cooling apparatus.

Figure 8 shows photos of the two integrations. For temperature determination, the infrared thermal photography and the thermocouple thermometer were used. Figure 9 shows positions of the measured points with symbols $T_{1}-T_{6}$ which are measured by using the thermocouple thermometer.

\section{Results and Discussion}

Heat pipe uses special technique for heat transfer and therefore receives an extremely large thermal conductivity. With the help of the two-phase flow in heat pipe, the vapor in heat pipe brings latent heat and directly transports to the remote condensing section. This special heat transfer property causes the discrete temperature distribution on the heat pipe. The heating and the condensing sections have the higher temperature than the middle thermal insulating section [7]. Figure 10 shows time dependent temperature distribution on the home-made square heat pipe without any cooling apparatus connection. Figure 10 indicates that the temperature distribution on the heat pipe is very uniform because it has extremely large thermal conductivity. Moreover, Figure 11 shows surface temperature distribution on the home-made square heat pipe heated in $350 \mathrm{sec}$ and indicates that the temperature on the condensing section is something higher than that on the middle thermal insulating section.

The special heat transfer property causes heat pipe to have high thermal conductivity, but it can be destroyed by integration with outside cooling plates. The connected outside cooling apparatus in the middle thermal insulating section forcedly takes heat away and causes the vapor inside heat pipe to be condensed earlier. Figure 12 shows time dependent temperature distribution on the home-made square heat pipe with isothermal temperature cooling water integrated in the middle position of the heat pipe. Figure 13 shows surface temperature distribution on the home-made square heat pipe heated in $500 \mathrm{sec}$. Figures 12 and 13 indicate that integration with isothermal cooling water has destroyed the original heat transfer behavior of the heat pipe and yields the copper-like heat transfer property. Figure 14 further shows infrared thermal photos of the two-dimensional temperature distribution on the home-made square heat pipe integrated with isothermal cooling water. Figure 14 clearly indicates that heat transfer property inside the heat pipe is destroyed by the outside isothermal cooling water and the vapor in heat pipe 
is condensed at the cooling position. The temperature on the remote condensing section is lower.

Figure 15 shows time dependent temperature distribution on the home-made square heat pipe integrated with aluminum cooling plates and Figure 16 shows its surface temperature distribution on the home-made square heat pipe heated in $500 \mathrm{sec}$. In comparison with Figures 15 and 16, the result shows good similarity. In other words, integration with cooling apparatus has destroyed the original heat transfer behavior of the heat pipe and yields the copper-like property.

Figures 17(a)-17(d) exhibit heat flux visualizations of heat pipe in water using color schlieren technique. Figures 17(a)17(d) clearly show that the heat in the middle thermal insulating section is taken away due to the surrounding water which serves as a cooling apparatus. This result gives good physical explanation of the forced thermal convection between heat pipe and the connected outside cooling apparatus in the middle thermal insulating section.

\section{Conclusion}

Experimental study on heat transfer characterizations of heat pipe influenced by outside cooling apparatus has been successfully carried out. The results show that the heat transfer behavior of a bare heat pipe is discrete. In general, the heating and the condensing sections of the bare heat pipe have higher temperature than the middle thermal insulating section. Integration with outside cooling apparatus has destroyed the heat transfer property of a heat pipe. The changed heat transfer property of the heat pipe is similar to the copper pipe. To improve the cooling efficiency of the heat pipe cooler, a modified structure of heat pipe should be designed to keep the original heat transfer behavior of heat pipe after integration with cooling plates.

\section{Conflict of Interests}

The authors declare that there is no conflict of interests regarding the publication of this paper.

\section{Acknowledgment}

The authors would like to acknowledge the financial support from the National Science Foundation of Taiwan, under Grant no. NSC98-2221-E-027-058.

\section{References}

[1] N. Narendran and Y. Gu, "Life of LED-based white light sources," IEEE/OSA Journal of Display Technology, vol. 1, no. 1, pp. 167-170, 2005.

[2] L. T. Yeh, "Review of heat transfer technologies in electronic equipment," Journal of Electronic Packaging, vol. 117, no. 4, pp. 333-339, 1995.

[3] M. S. El-Genk and H. Lianmin, "An experimental investigation of the transient response of a water heat pipe," International Journal of Heat and Mass Transfer, vol. 36, no. 15, pp. 3823-3830, 1993.
[4] R. Tummala, Fundamentals of Micro-Systems Packaging, McGraw-Hill, New York, NY, USA, 2002.

[5] S.-C. Lin, F.-S. Chuang, and C.-A. Chou, "Experimental study of the heat sink assembly with oblique straight fins," Experimental Thermal and Fluid Science, vol. 29, no. 5, pp. 591-600, 2005.

[6] W. Jia and H.-H. Qiu, "Experimental investigation of droplet dynamics and heat transfer in spray cooling," Experimental Thermal and Fluid Science, vol. 27, no. 7, pp. 829-838, 2003.

[7] C.-C. Ting, J.-N. Lee, and C.-C. Chen, "Heat transfer characterizations of heat pipe in comparison with copper pipe," Journal of Heat Transfer I, vol. 131, no. 3, Article ID 033109, pp. 1-6, 2009.

[8] A. Bejan and E. Sciubba, "The optimal spacing of parallel plates cooled by forced convection," International Journal of Heat and Mass Transfer, vol. 35, no. 12, pp. 3259-3264, 1992.

[9] R.-H. Yeh and M. Chang, "Optimum longitudinal convective fin arrays," International Communications in Heat and Mass Transfer, vol. 22, no. 3, pp. 445-460, 1995.

[10] C. A. Soule, Future Trends in Heat Sink Design, Electronics Cooling, 2001.

[11] R. Viswanath, V. Wakharkar, A. Watwe, and V. Lebonheur, "Thermal performance challenges from silicon to systems," Intel Technology Journal, vol. Q3, 2000.

[12] Y.-H. Lin, S.-W. Kang, and H.-L. Chen, "Effect of silver nanofluid on pulsating heat pipe thermal performance," Applied Thermal Engineering, vol. 28, no. 11-12, pp. 1312-1317, 2008.

[13] S. Khandekar, Y. M. Joshi, and B. Mehta, "Thermal performance of closed two-phase thermosyphon using nanofluids," International Journal of Thermal Sciences, vol. 47, no. 6, pp. 659-667, 2008.

[14] L. L. Vasiliev, "Heat pipes in modern heat exchangers," Applied Thermal Engineering, vol. 25, no. 1, pp. 1-19, 2005. 

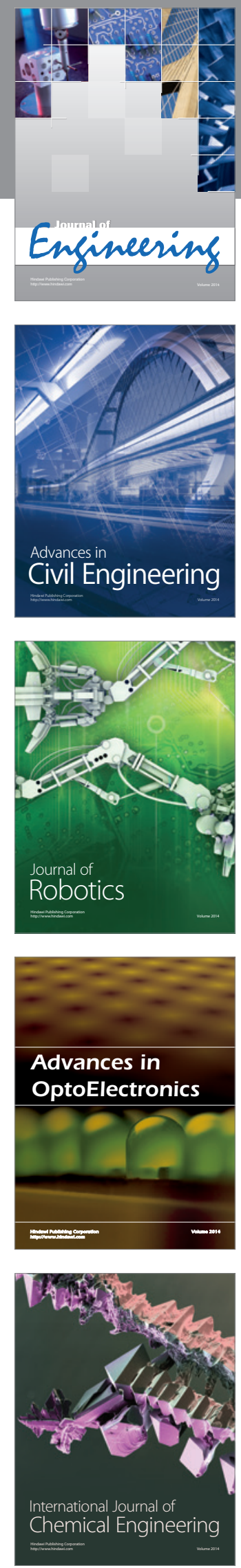

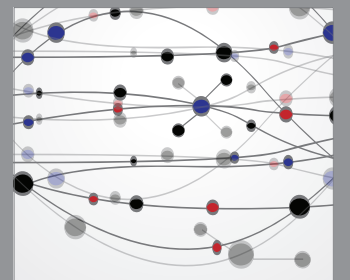

The Scientific World Journal
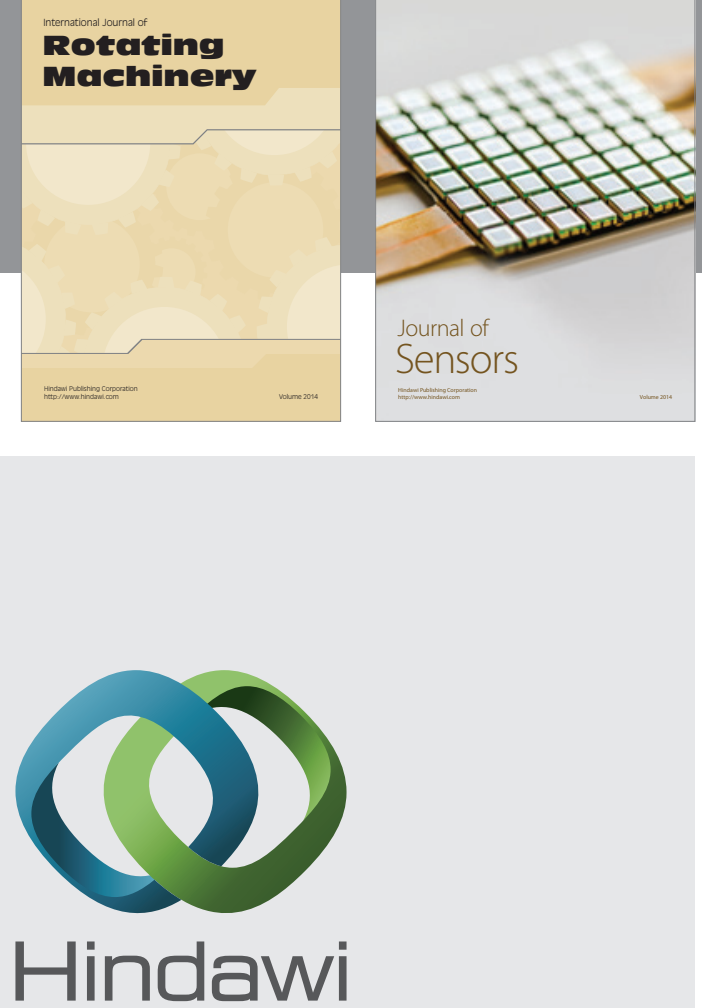

Submit your manuscripts at http://www.hindawi.com
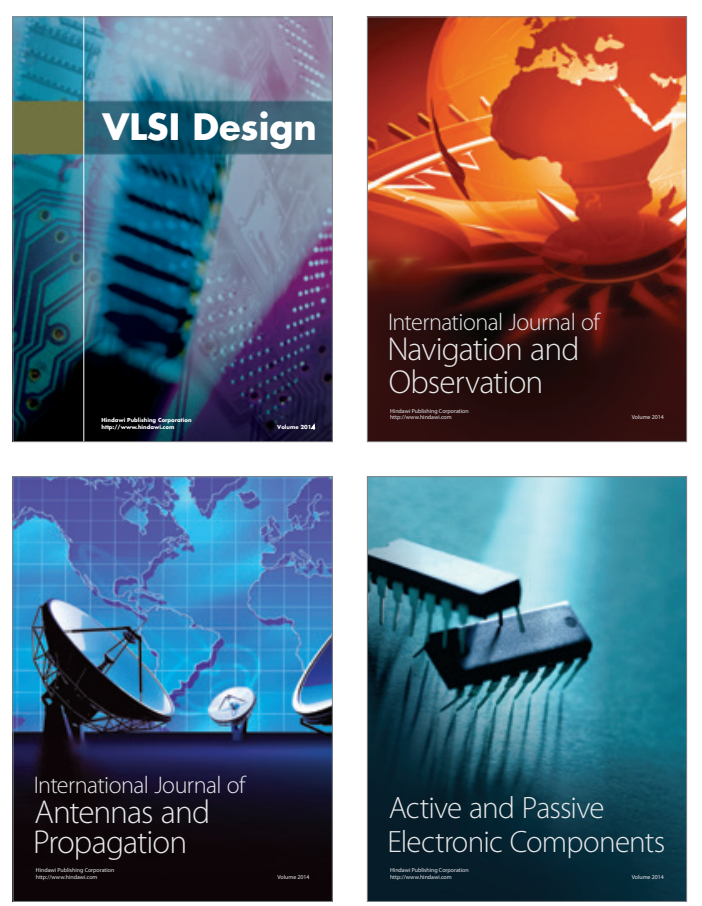
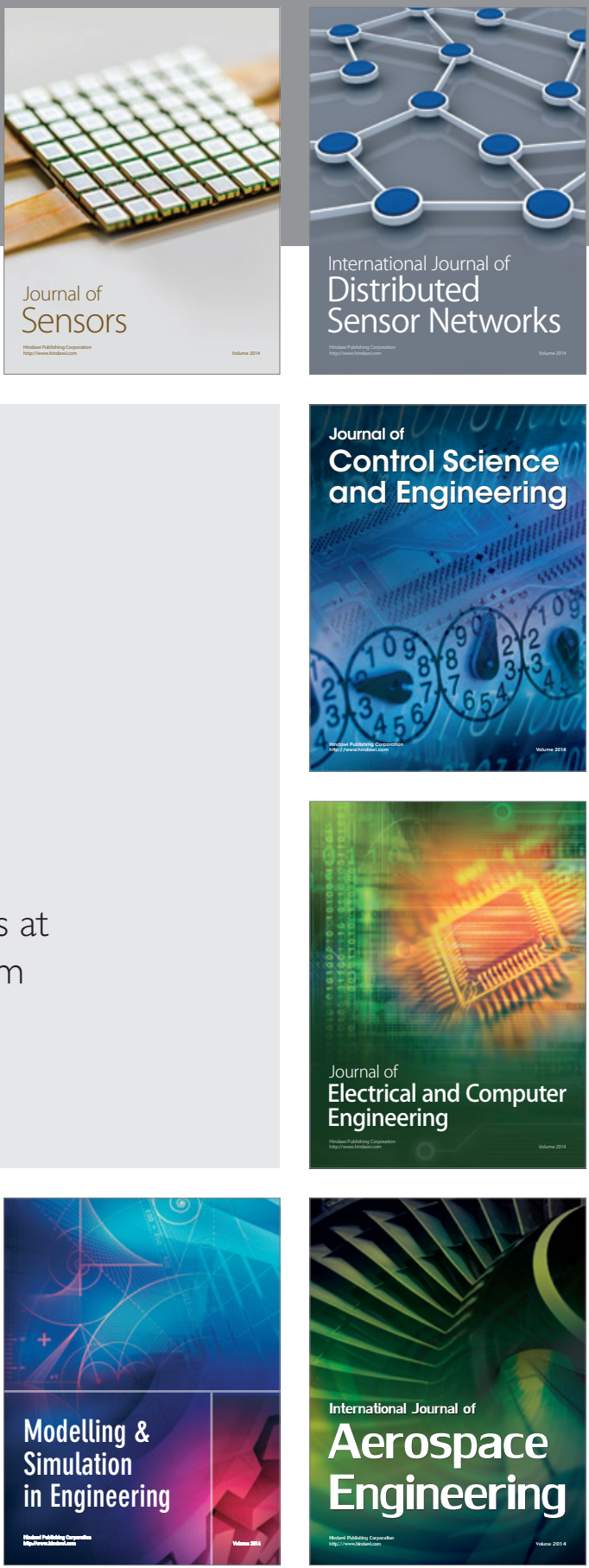

Journal of

Control Science

and Engineering
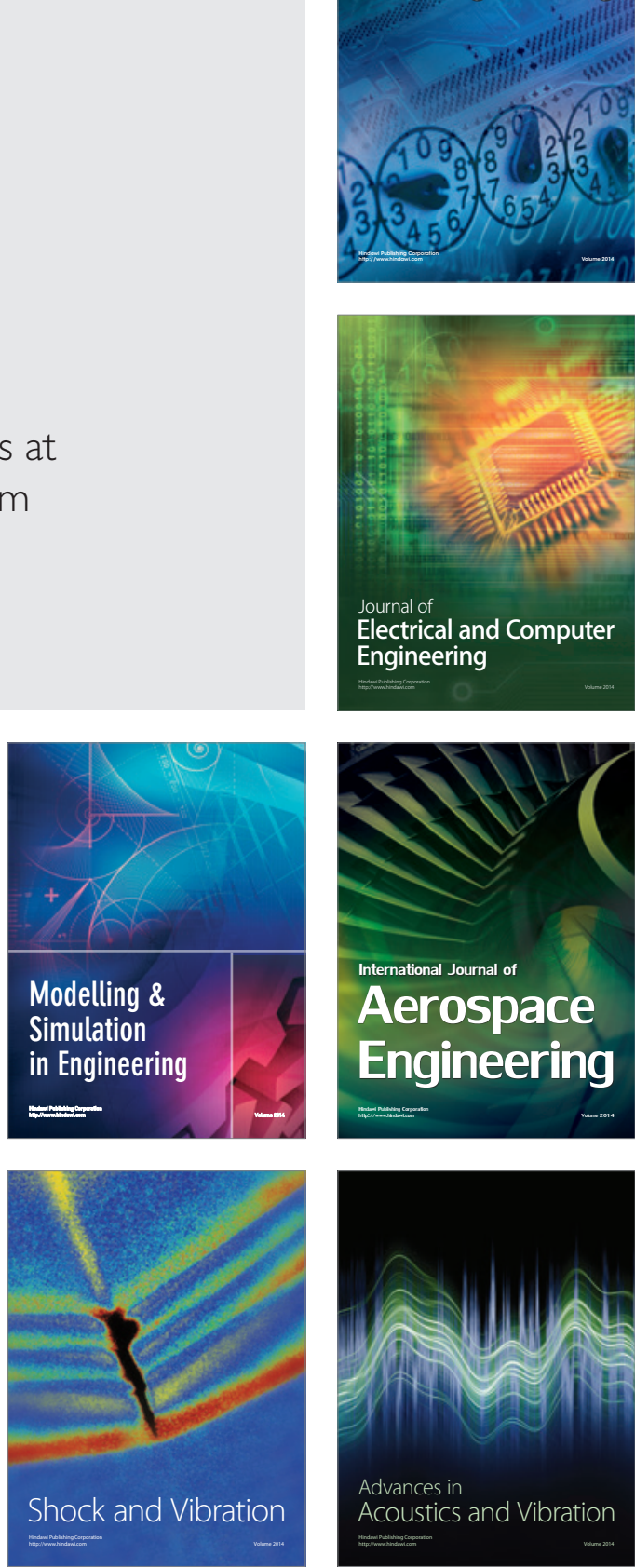